\title{
Aborted Sudden Death Due to Severe Ventricular Arrhythmia in Timothy Syndrome
}

\author{
Erivelton Nascimento, ${ }^{1,2,3}$ Carollina Fernandes Tinoco, ${ }^{3}{ }^{\circledR(}$ Camila Diniz Silva, $^{3(-)}$ Fabiana Ferreira Mitidieri Cortez, ${ }^{2}$ \\ Renato Kaufman² \\ Universidade Federal Fluminense - Hospital Universitário Antonio Pedro, ${ }^{1}$ Niterói, RJ - Brazil. \\ Instituto Estadual de Cardiologia Aloysio de Castro, ${ }^{2}$ Rio de Janeiro, RJ - Brazil. \\ Centro Universitário de Volta Redonda - Escola de Ciências Medicas de Volta Redonda, ${ }^{3}$ Volta Redonda, RJ - Brazil.
}

\begin{abstract}
Timothy Syndrome is a rare autosomal dominant multisystem genetic condition. The CACNA1C gene, codifier of the CaV1.2 calcium channel, is affected, resulting in the loss of voltage-dependent calcium channel inactivation. Relevant clinical characteristics: (1) corrected QT interval greater than $480 \mathrm{~ms}$; (2) syndactyly. Death often occurs during childhood, and results from ventricular tachyarrhythmias. This study presents the case of a female newborn who suffered a cardiorespiratory arrest, secondary to ventricular arrhythmia. A prolonged QT interval, combined with 2:1 AV block, was also identified, requiring a definitive cardiac pacemaker implant that, during inpatient care, developed pulmonary sepsis, followed by death.
\end{abstract}

\section{Introduction}

Timothy Syndrome (TS) or LQTS8, is a very rare multisystem genetic condition (incidence: $\left.1.5 / 10^{8}\right)^{1}$, first reported in $1992 .^{2}$ The inheritance pattern is autosomal dominant, ${ }^{3}$ and it is caused by a de novo missense mutation in exon 8A. ${ }^{4}$ TS type 2 stems from a missense mutation on an alternatively spliced exon 8 , with different phenotypical expression, which will not be addressed in this work. TS is easily identifiable, as the typical phenotype permits a very high degree of clinical

\section{Keywords}

Long QT Syndrome; Syndactyly/genetics; Arrhythmias Cardiac/complications; Death Sudden; Child. suspicion long before the results of confirmatory genetic testing are available.

Characterized by high mortality, and an average age of death at 2.5 years, TS represents a diagnostic challenge. ${ }^{5}$ Mortality in TS is considered multifactorial and sudden cardiac death is the main cause of death. ${ }^{6}$ The most reliable clinical evidence available on the subject is level 4,7 i. e. case series.

The pathogenic variant of the CACNA1C (p.Gly406Arg) can be identified through molecular testing. ${ }^{8}$ It encodes the calcium channel Cav1.2, a voltage-dependent L-type channel, capable of increasing the cytosolic ion concentration and of triggering cell excitation. This fact justifies the sustained calcium depolarization currents during the plateau phase and the prolonged QT interval. Thus, arrhythmogenesis in TS derives from the lack of Cav1.2 inactivation. ${ }^{9}$

With the prolonged depolarization of the ventricular myocytes, early afterdepolarizations surge. Initially, they manifest as ventricular extrasystole and later as ventricular tachycardia (VT). ${ }^{10}$ Once converted into a functional reentry circuit, this electrical activity can degenerate into a polymorphic ventricular tachycardia, culminating in sudden death. ${ }^{11}$

Knowledge, expertise, and solid academic grounding on clinical manifestations of TS contribute to early diagnosis, as well as to the prevention of negative outcomes. TS patients also demand specialized care during anesthetic induction, due to a specifically increased risk of malignant arrhythmias in this group. ${ }^{12}$ The aim of this work is to report a case of a newborn that presented VT, associated with the prolongation of the QT interval and phenotypic manifestations of TS. 


\section{Case Report}

This study examined a female child, born at term, with a birth weight of $3020 \mathrm{~g}$, 40 weeks old, presenting syndactyly in hands and feet and posteriorly identified long QT interval (Figure 1).

At the age of 5 days, the patient presented cardiorespiratory arrest (CRA), secondary to VT. After electrical cardioversion, a prolonged QT interval was identified, intercalated with 2:1 AV block and hypoglycemic episodes. The transthoracic echocardiogram (TTE) revealed an ejection fraction at $53 \%$ and a structurally normal heart. At the age of 21 days, a dual chamber epicardial pacemaker was implanted.

Two days after surgery, the patient developed respiratory discomfort. The X-ray showed a large chylothorax pleural effusion to the right, followed by thoracic drainage. The patient was sedated and put under mechanical ventilation support, propranolol (5.0mg/kg/day), furosemide (infusion at $0.2 \mathrm{mg} / \mathrm{kg} / \mathrm{h}$ ), and antimicrobial prophylactic therapy with cefazolin and vancomycin. No neurological abnormalities were observed.
For presenting tachyarrhythmia in the pre and postoperative periods, the patient was admitted to a quaternary care hospital, where the device was electronically programmed in DDD mode (Figure 2). Beta-blocker therapy was maintained, and clinical followup was provided.

At the age of 44 days, the patient presented assisted CRA in asystole. At this point, proper care was provided, and the CRA was reversed. TTE revealed mild right ventricular hypertrophy. During hospitalization, the patient developed pulmonary sepsis and died.

\section{Discussion}

The CACNA1C mutated gene is expressed in multiple cell types, ${ }^{13}$ and the clinical presentation may vary. However, special attention should be driven to core findings: a QTc interval of greater than $480 \mathrm{~ms}$ and syndactyly, which can be cutaneous or skeletal, uni or bilateral, of hands or feet. ${ }^{14}$ As displayed on Figure 1, the first finger is spared, while only the second and third toes are usually affected. ${ }^{12}$

Many patients express facial dysmorphisms, such as flat nasal bridge, receding upper jaw, low auricular

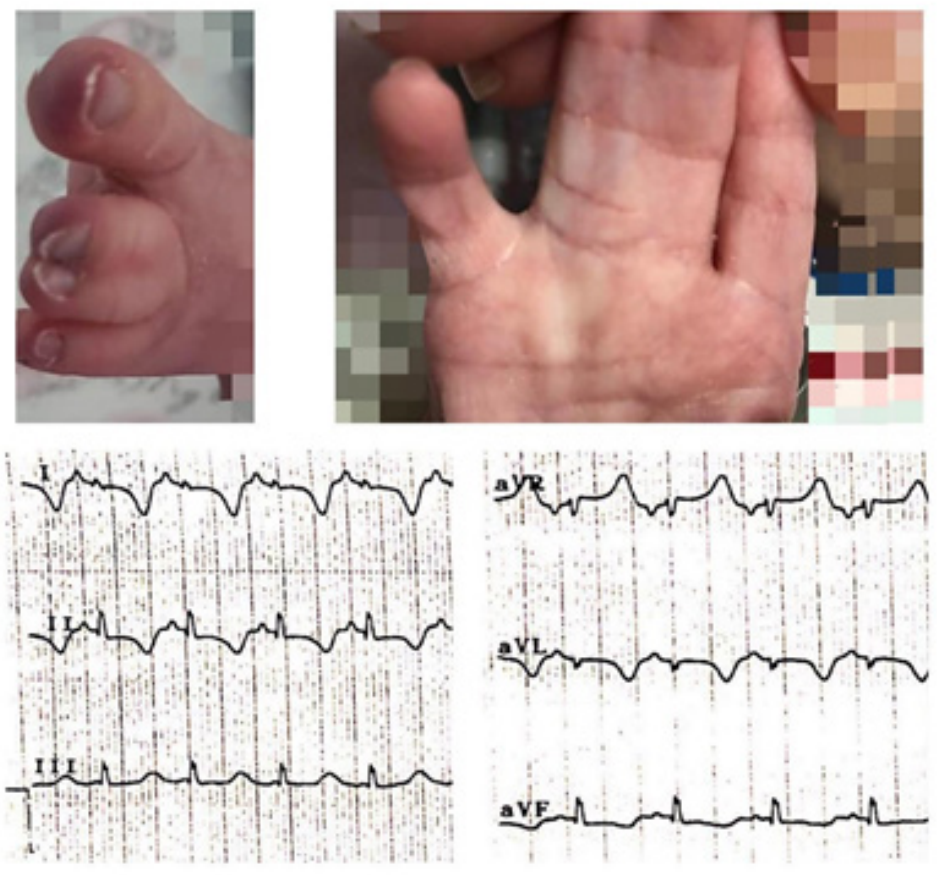

Figure 1 - Superior section: syndactyly of foot and hand, respectively. Inferior section: ECG shows long corrected QT (QTc-interval: $514 \mathrm{~ms}$ ) in peripheral leads. 


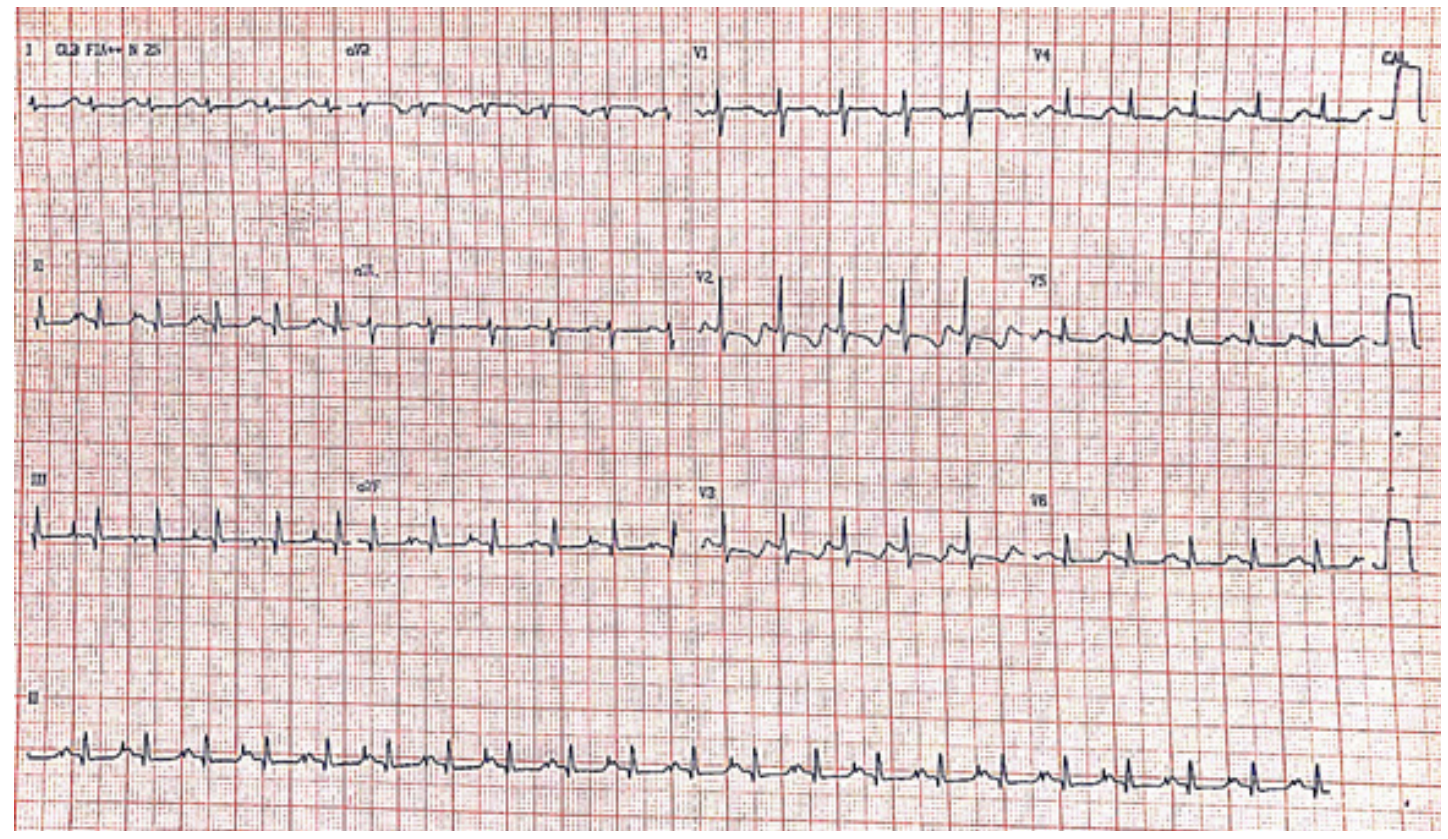

Figure 2 - Electrocardiographic findings in our patient with TS. A standard 12-lead electrocardiogram shows QTc-interval of 365ms, after pacemaker implantation in DDD stimulation mode.

implantation, and round face. Immune deficiency, cognitive abnormalities and autism have also been reported. ${ }^{3}$ The patient presented no such feature.

Since cardiac malformations (such as patent foramen ovale, tetralogy of Fallot, or hypertrophic cardiomyopathy) are frequently observed in TS patients, fetal echocardiography stands out as an important screening tool. ${ }^{11}$ Although any of these findings, during or after prenatal care, should raise diagnostic suspicion, especially in mosaic parents, current evidence does not support routine ECG testing for children referred for syndactyly release..$^{15}$ Electrocardiographic screening in newborns with syndactyly can lead to early clinical suspicion.

Considering, on the one hand, the limitations of existing studies due to the aforementioned aspects and, on the other hand, that the best clinical decision consists of a triad, composed of (a) best available science (b) healthcare professional's clinical experience; and (c) the patient's values, ${ }^{16}$ we recommend decision-making regarding complementary exams to be individualized in such cases.

Neurological findings are extremely common in TS, summing up to $80 \%$ of the patients. ${ }^{17}$ This might be related to the essential role of L-type calcium channels on the developing brain. ${ }^{17}$ Anomalous phosphorylation or increased calcium cell inflow leads to the neurotoxicity in TS patients. ${ }^{18}$ No atypical neurological findings were observed.

As seen in this case, hypoglycemia is common in TS and is allegedly linked to the activation of LTCs on pancreatic B-cells. The same study suggests that some unsuccessful resuscitations might have been related to hypoglycemia. ${ }^{1}$

Therapy is frequently based on monotherapy with betablockers (BBs). BBs are the treatment of choice for LQTS patients ${ }^{19}$ and were adopted in this case. The patient presented a 2:1 AV block, requiring a dual chamber pacemaker, in order to maintain cardiac output and prevent variation of the QT. ${ }^{20}$ Therapeutic options include implantable cardiodefibrillators (ICDs) ${ }_{,}^{6}$ considered in symptomatic LQTS patients not to be responsible for or tolerable to BBs, in order to avoid sudden cardiac death.

Although there is an increasing trend in pediatric ICD implantation, limited evidence on population characteristics, complications, and survival is available, ${ }^{21}$ especially among newborns. As there are no specific guidelines concerning pediatric populations, adult indications are applied in a practical sense. Recent studies suggest that non-transvenous ICD (NT-ICD) is safe and effective in infants and young children. ${ }^{22}$ 
The therapeutic decision-making process must consider anthropometric parameters and lead characteristics. ${ }^{23,24}$ Thus, in small body patients, NT-ICDs are often the only option. ${ }^{22-25}$ It is possible to use either an abdominal device and subcutaneous shock coil, or a subcardiac device and a pleural shock coil. ${ }^{25}$

Clinical evidence shows that infectious diseases are the second leading cause of death in TS. ${ }^{11}$ In the present case report, the patient presented a reversed CRA, and later developed septic lung disease, culminating in death.

\section{Conclusion}

Timothy syndrome is a very rare genetic condition, even though it is easily identifiable, as the typical phenotype allows for a very high degree of clinical suspicion long before the results of confirmatory genetic testing are available. The phenotypic findings of syndactyly of hands and feet associated with electrocardiographic records of QT prolongation are frequent. Its high lethality is mainly related to ventricular arrhythmic events, and, in this scenario, the use of beta-blockers and a definitive pacemaker are part of the therapeutic mainstay. Early diagnosis can prevent negative outcomes and should be based on clinical suspicion. Fetal echocardiography stands out as an important screening tool in mosaic parents, but current evidence does not support routine ECG testing for children referred for syndactyly release.

\section{References}

1. Walsh MA, Turner C, Timothy KW, Seller N, Hares DL, James AF, et al. A multicentre study of patients with Timothy Syndrome. Europace. 2018;20(2);377-85.

2. Reichenbach H, Meister EM, Theile H. The heart-hand syndrome. A new variant of disorders of heart conduction and syndactylia including osseous changes in hands and feet. Kinderarztl Prax. 1992;60(2);54-6.

3. Online Mendelian Inheritance in Man, OMIM®. Johns Hopkins University, Baltimore, MD. MIM Number: 601005: Jun 6; 2019.[acesso em 03 set. 2020]. Disponível em: https://www.omim.org/entry/601005

4. Splawski I, Timothy KW, Decher N, Kumar P, Sachse FB, Beggs Al, et al. Severe arrhythmia disorder caused by cardiac L-type calcium channel mutations. Proc Natl Acad. Sci USA. 2005;102(23):8089-96.

5. Han D, Xue X, Yan Y, Li G. Dysfunctional Cav1.2 channel in Timothy syndrome, from cell to bedside. Exp Biol Med (Maywood). 2019;244(12);960-71.

6. Dufendach KA, Timothy K, Ackerman MJ, Blevins B, Pflaumer A, Etheridge S, et al. Clinical outcomes and modes of death in Timothy Syndrome: a Multicenter International Study of a Rare Disorder. JACC Clin Electrophysiol. 2018;4(4);459-66.

\section{Author Contributions}

Conception and design of the research: Nascimento E, Silva CD, Tinoco CF, Cortez FFM, Kaufman R. Acquisition of data: Nascimento E, Silva CD, Tinoco CF, Cortez FFM, Kaufman R. Analysis and interpretation of the data: Nascimento E, Silva CD, Tinoco CF, Cortez FFM, Kaufman R. Writing of the manuscript: Nascimento E, Silva CD, Tinoco CF. Critical revision of the manuscript for intellectual content: Nascimento E, Silva CD, Tinoco CF, Cortez FFM, Kaufman R.

\section{Potential Conflict of Interest}

No potential conflict of interest relevant to this article was reported.

\section{Sources of Funding}

There were no external funding sources for this study.

\section{Study Association}

This study is not associated with any thesis or dissertation work.

\section{Ethics Approval and Consent to Participate}

This article does not contain any studies with human participants or animals performed by any of the authors.

7. OCEBM Levels of Evidence Working Group. The Oxford 2011 Levels of Evidence. Oxford Centre for Evidence-Based Medicine.. [acesso em 01 abr. 2020]. Disponível em: https://www.cebm.net/wp-content/ uploads/2014/06/CEBM-Levels-of-Evidence-2.1.pdf

8. Corona-Rivera JR, Barrios-Prieto E, Nieto-Garcia R, Bloise R, Priori S, Napolitano C, et al. Unusual retrospective prenatal findings in a male newborn with Timothy syndrome type 1. Eur J Med Genet. 2015;58 (67);332-5.

9. Dick IE, Joshi-Mukherjee R, Yang W, Yue DT. Arrhythmogenesis in Timothy Syndrome is associated with defects in $\mathrm{Ca}(2+)$-dependent inactivation. Nat Commun. 2016 Jan 29;7;10370.

10. Bai J, Wang K, Li Q, Yuan Y, Zhang H. Pro-arrhythmogenic effects of CACNA1C G1911R mutation in human ventricular tachycardia: insights from cardiac multi-scale models. Sci Rep. 2016 Aug 9;6:31262.

11. Napolitano C, Splawski I, Timothy K, Bloise R, Priori S. Timothy Syndrome. Gene Reviews [internet] feb 15, 2006; [acesso em 30 mar. 2020]. Disponível em: https:/www.ncbi.nlm.nih.gov/sites/books/NBK1403/

12. Nathan AT, Antzelevitch C, Montenegro LM, Vetter VL. Case scenario: anesthesia-related cardiac arrest in a child with Timothy syndrome. Anesthesiology. 2012;117(5):1117-1126. 
13. Splawski I, Timothy KW, Sharpe LM, Decher N, Kumar P, Bloise R, et al. $\mathrm{Ca}(\mathrm{V}) 1.2$ calcium channel dysfunction causes a multisystem disorder including arrhythmia and autism. Cell. 2004;119(1):19-31.

14. Fragata CS, Moreira DAR, Andalaft RB, Habib RG, Khader HM, Saboya PV, et al. Timothy syndrome: case report. J Card Arrhythm. 2014;27(4):264-7.

15. Nuzzi LC, Pike CM, Lewine EB, Cerrato FE, Alexander ME, Ferrari LR, et al. Preoperative Electrocardiograms for nonsyndromic children with hand syndactyly. J Hand Surg Am.2015;40(3):452-5.

16. Tenny S, Varacallo M. Evidence Based Medicine (EBM) [Updated 2020 Feb 17]. In: StatPearls [Internet]. Treasure Island (FL): StatPearls Publishing 2020..[acesso em 01 abr. 2020]. Disponível em: https://www.ncbi.nlm.nih. gov/books/NBK470182/

17. Dolmetsch R. Excitation-transcription coupling: signaling by ion channels to the nucleus. Sci STKE. 2003 Jan 21;(166):PE4.

18. Erxleben C, Liao Y, Gentile S, Chin D, Gomez-Alegria C, Mori Y, et al Cyclosporin and Timothy syndrome increase mode 2 gating of CaV1.2 calcium channels through aberrant phosphorylation of S6 helices. Proc Natl Acad Sci USA. 2006;103(10):3932-7.

19. Duncan G, Firth K, George V, Hoang MD, Staniforth A, Smith G, et al. Drug-mediated shortening of action potentials in LQTS2 human induced pluripotent stem cell-derived cardiomyocytes. Stem Cells Dev. 2017;26(23):1695-1705
20. Gao Y, Xue X, Hu D, Liu W, Yuan Y, Sun H, et al. Inhibition of late sodium current by mexiletine: a novel pharmotherapeutical approach in timothy syndrome. Circ Arrhythm Electrophysiol. 2013;6(3):614-22.

21. Baskar S, Bao H, Minges KE, Spar DS, Czosek RJ. Characteristics and outcomes of pediatric patients who undergo placement of implantable cardioverter defibrillators: insights from the National Cardiovascular Data Registry. Circ Arrhythm Electrophysiol. 2018;11(9):e006542.

22. Müller MJ, Dieks JK, Backhoff D, Schneider HE, Ruschewski W, Tirilomis T, et al. Efficacy and safety of non-transvenous cardioverter defibrillators in infants and young children. J Interv Card Electrophysiol. 2019;54(2):151-59.

23. Bar-Cohen Y, Berul CI, Alexander ME, Fortescue EB, Walsh EP, Triedman JK, et al. Age, size, and lead factors alone do not predict venous obstruction in children and young adults with transvenous lead systems. J Cardiovasc Electrophysiol. 2006;17(7):754-9.

24. Sanjeev S, Karpawich PP. Superior vena cava and innominate vein dimensions in growing children: an aid for interventional devices and transvenous leads. Pediatr Cardiol. 2006;27(4): 414-9.

25. Rella V, Parati G, Crotti L. Sudden cardiac death in children affected by cardiomyopathies: an update on risk factors and indications at transvenous or subcutaneous implantable defibrillators.. Front Pediatr. 2020 Apr 3;8:139. 